\title{
Effect of Casting Temperature and Atmosphere on Castability of Ni-Cr Alloys: A Comparative Study with Direct Flame Casting Method
}

\author{
Osvaldo Luiz Bezzon*, Celso de Barros, Valéria Oliveira Pagnano, Natércia Carreira Soriani \\ Department of Dental Materials and Prostheses, School of Dentistry of Ribeirão Preto, \\ University of São Paulo, Ribeirão Preto - SP, Brazil
}

Received: January 24, 2006; Revised: March 9, 2006

\begin{abstract}
The purpose of this study was to compare the effect of casting temperature and atmosphere on the castability of three Ni-Cr alloys against direct flame casting method. Vera Bond (VB), Vera Bond 2 (VB2) and Wiron 99 (W99) were cast at three temperatures: VB and VB2 $\left(1310{ }^{\circ} \mathrm{C}, 1340{ }^{\circ} \mathrm{C}\right.$ and $\left.1370{ }^{\circ} \mathrm{C}\right)$; W99 $\left(1400{ }^{\circ} \mathrm{C}, 1430{ }^{\circ} \mathrm{C}\right.$ and $1460{ }^{\circ} \mathrm{C}$ ) in atmosphere, vacuum and direct flame. Each alloy was cast in seven different conditions. Castability was assessed by the method that verifies the alloy potential to reproduce a nylon mesh. Kruskal-Wallis test demonstrated for VB, while there was no influence in the temperature range, castability was greater by vacuum (99.3\%) than by direct flame $(96.2 \%)$ and atmosphere $(93.06 \%)$. For VB2, castability was greater at evaluated temperatures $\left(1370{ }^{\circ} \mathrm{C}=94.4 \%, 1340{ }^{\circ} \mathrm{C}=91.15 \%\right.$ and $\left.1310{ }^{\circ} \mathrm{C}=87.9 \%\right)$ than direct flame $(77.8 \%)$; related vacuum $(97.33 \%)$ obtained better values than atmosphere $(84.6 \%)$ and direct flame. For W99, while atmosphere had no influence, castability was higher at $1460{ }^{\circ} \mathrm{C}(84.3 \%)$ than at other temperatures $\left(1430{ }^{\circ} \mathrm{C}=70.3 \%, 1400{ }^{\circ} \mathrm{C}=37.05 \%\right)$ and direct flame (62.5\%). Comparison among interactions showed that for all alloys it was possible to significantly increase the filling percentage of the mold in a comparative manner with the direct flame cast method.
\end{abstract}

Keywords: castability, $\mathrm{Ni}$-Cr alloys, casting temperature, casting atmosphere

\section{Introduction}

The development of alloys, by changing noble metal alloys into semi-noble metal alloys or from palladium- or silver-based alloys, shows that to some degree researchers are not satisfied with dental base metal alloys ${ }^{1}$, owing to the fact that they are difficult to burnish and polish, and in some cases, because of sensitivity ${ }^{2}$. However, chromium-containing alloys, such as $\mathrm{Ni}-\mathrm{Cr}$ and $\mathrm{Co}-\mathrm{Cr}$ alloys, continue to be used worldwide mainly as a result of their low cost compared with gold or palladium alloys. Chromium and other components such as niobium, molybdenum and titanium provide great corrosion resistance, which has demonstrated good clinical performance of these alloys.

The castability of dental alloys is also a factor to be considered, since it is directly related to casting restoration success. Poor or inconsistent castability often leads to costly laboratory remakes of restorations ${ }^{3}$. Although the castability, as a property of dental casting alloys, may be affected by several external factors ${ }^{4}$, castability values, obtained by all methods, may be reflected by the variations effect in composition ${ }^{5}$, which also determines, in a general overview, the properties of dental alloys.

Chemical elements such as $\mathrm{Be}, \mathrm{Nb}$ and Mo contribute to the castability property of base metal alloys ${ }^{6,7}$, being that $\mathrm{Be}$ is an important factor with which to improve the melting of the base metal alloys ${ }^{8}$. Howbeit, correct handling of any material also contributes to clinical success. Different metal-ceramic alloys (gold-, palladium-, and nickel-chromium-based) react differently to various factors involved in the casting method ${ }^{9}$. In general, castability may also be improved by higher mold temperature ${ }^{10}$, application of vacuum and by increasing the temperature of the melt ${ }^{11,12}$.

However, the incorrect use of a direct gas-oxygen flame may affect the properties of the alloys, despite its ideal formulation and mold temperature, due to of the possibility of over- or under-melting temperature as a function of casting method limitation.
Thus, improvement of the alloy composition and its handling play a fundamental role not only in its physical and mechanical properties, but also in the quality of casting. Within this context, the use of casting machines that enables closing the control of casting conditions may represent a significant contribution to improving the quality of dental restorations with base metal alloys. Manufacturers generally recommend an ideal casting temperature or temperature range. However, no information has been given concerning casting atmosphere, considering that casting in the presence of oxygen may cause oxidation of metal elements with substantial reaction power.

Considering that, when using direct flame casting methods, temperature variations can occur as a consequence of the technician's visual interpretation, the objective of this work was to evaluate the effect of minor temperature variations on the castability of three commercially available base metal alloys, as well as to evaluate the effect of casting atmosphere.

\section{Materials and Methods}

Three commercial Ni-Cr alloys (Table 1) were evaluated. The method proposed by Hinman et al. ${ }^{13}$, which consists of verifying the potential of dental alloys to reproduce the mesh of a nylon net used as the casting standard, was used (Figure 1).

Sample tests of each material were cast from $10.0 \times 10.0 \mathrm{~mm}$ plastic patterns with 100 empty spaces and were included in a phosphate-bonded investment (Termocast, Polidental, Sao Paulo, SP, Brazil). Thermal cycling followed, according to manufacturer recommendations: 1) At speed $5{ }^{\circ} \mathrm{C} / \mathrm{min}$, heating at $300{ }^{\circ} \mathrm{C}$ and maintaining for 30 minutes; 2 ) heating at $950{ }^{\circ} \mathrm{C}$, at the same speed, and maintaining for 40 minutes.

Ten sample tests of each material were cast in an induction casting machine (Neutrodyn Easyti, Flli Manfredi - 10060 San Secondo Di 
Table 1. Composition of the alloys (mass \%).

\begin{tabular}{lccccccccc}
\hline Alloy & $\mathrm{Ni}$ & $\mathrm{Co}$ & $\mathrm{Cr}$ & $\mathrm{Nb}$ & $\mathrm{Fe}$ & $\mathrm{Mo}$ & $\mathrm{Be}$ & $\mathrm{Si}$ & $\mathrm{Al}$ \\
\hline VB* & $\mathrm{Bal}$ & 0.45 & 12.60 & - & - & 5.0 & 1.95 & - & 2.90 \\
VB2* & $\mathrm{Bal}$ & - & 11.50 & 4.25 & - & 3.5 & - & 3.5 & 2.25 \\
W99** & $\mathrm{Bal}$ & - & 22.50 & 1.00 & - & 9.5 & - & 1.0 & - \\
\hline
\end{tabular}

*Aalba Dent Inc., Cordelia CA, USA

**Bego, Bremen, Germany

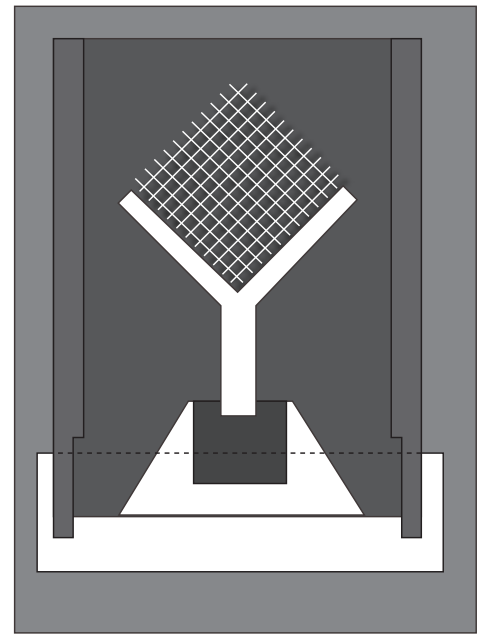

Figure 1. Schematic presentation of nylon net pattern used for preparation of sample tests. Dimensions: $10 \times 10 \mathrm{~mm}$, and 100 spaces.

Pinerolo, Italy) for both under vacuum and non-controlled atmosphere at three temperatures: VB and VB2 $\left(1310^{\circ} \mathrm{C}, 1340^{\circ} \mathrm{C}\right.$ and $\left.1370{ }^{\circ} \mathrm{C}\right)$; W99 $\left(1400{ }^{\circ} \mathrm{C}, 1430{ }^{\circ} \mathrm{C}\right.$ and $\left.1460{ }^{\circ} \mathrm{C}\right)$ and by direct flame, resulting in seventy sample tests for each material. The cast conditions are summarized in Table 2. The temperature range was determined in preliminary tests, considering the manufacturer's recommendations and visual control of molten alloy within the crucible before centrifugation. For each alloy the highest temperature was determined within a safety limit, without any evidence of over heating. In the induction machine, at the moment the alloy reached the pre-selected temperature, the same torque for centrifugation was used for all castings, i.e., no heat-soak time was used. Ten sample tests of each material were also cast by a well-experienced technician, following the traditional casting method on a gas-oxygen flame and centrifugation. After checking the validity conditions, a nonparametric test was selected for the analysis of results. Kruskal-Wallis multiple range test was performed $(\mathrm{P}<0.05)$ in the different casting conditions for reasons of comparison.

\section{Results}

The castability results are presented for each alloy as a box plot in Figures 2 to 4. Statistical analysis was performed comparing the results of direct flame cast method (Df) with temperature variation disregarding casting atmosphere (Table 3), and casting atmosphere disregarding temperature (Table 4). Comparison was also performed between Df and different temperature/atmosphere interactions (Table 5).

Kruskal-Wallis test showed that for VB, while the range of temperatures considered did not have a significant effect on castability (Table 3 ), the filling of the mold in vacuum casting conditions $(99.3 \%)$ was higher $(\mathrm{P}<0.01)$ than under both atmosphere casting conditions $(93.06 \%)$ and Df (96.2\%). There was no difference between
Table 2. The cast conditions and abbreviations.

\begin{tabular}{|c|c|c|c|}
\hline \multirow{2}{*}{$\frac{\text { Alloy }}{\text { VB and VB2 }}$} & \multicolumn{2}{|c|}{ Cast condition } & \multirow{2}{*}{$\frac{\text { Abbreviation }}{\text { vc1370 }}$} \\
\hline & $1370{ }^{\circ} \mathrm{C}$ & vacuum & \\
\hline & & atmosphere & atm1370 \\
\hline & $1340^{\circ} \mathrm{C}$ & vacuum & vc1340 \\
\hline & & atmosphere & atm1340 \\
\hline & $1310^{\circ} \mathrm{C}$ & vacuum & vc1310 \\
\hline & & atmosphere & atm1310 \\
\hline & Direct flame & & Df \\
\hline \multirow[t]{7}{*}{ W99 } & $1460^{\circ} \mathrm{C}$ & vacuum & vc1460 \\
\hline & & atmosphere & atm1460 \\
\hline & $1430{ }^{\circ} \mathrm{C}$ & vacuum & vc1430 \\
\hline & & atmosphere & atm1430 \\
\hline & $1400^{\circ} \mathrm{C}$ & vacuum & vc1400 \\
\hline & & atmosphere & atm1400 \\
\hline & Direct flame & & Df \\
\hline
\end{tabular}

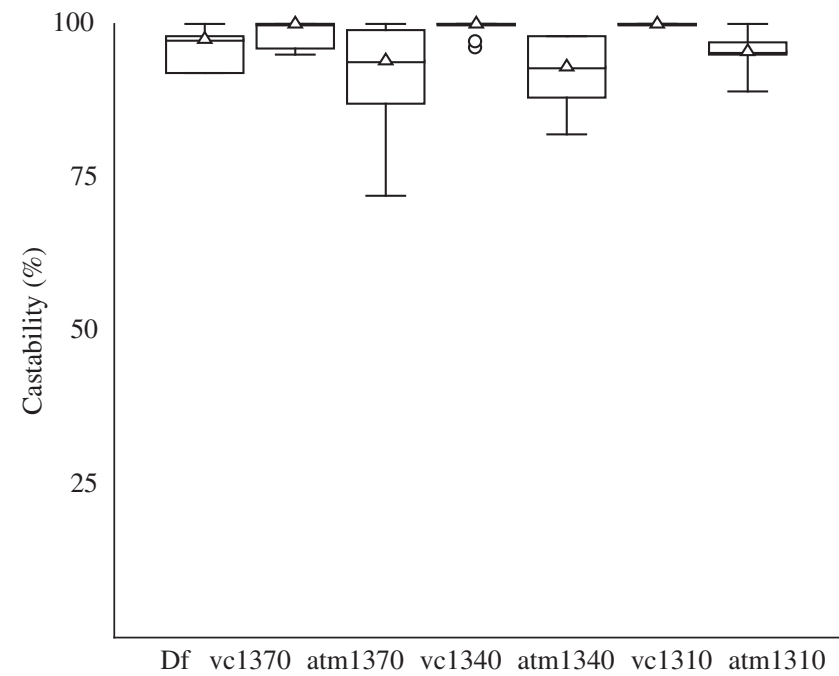

Figure 2. Box plot of castability values of VB alloy.

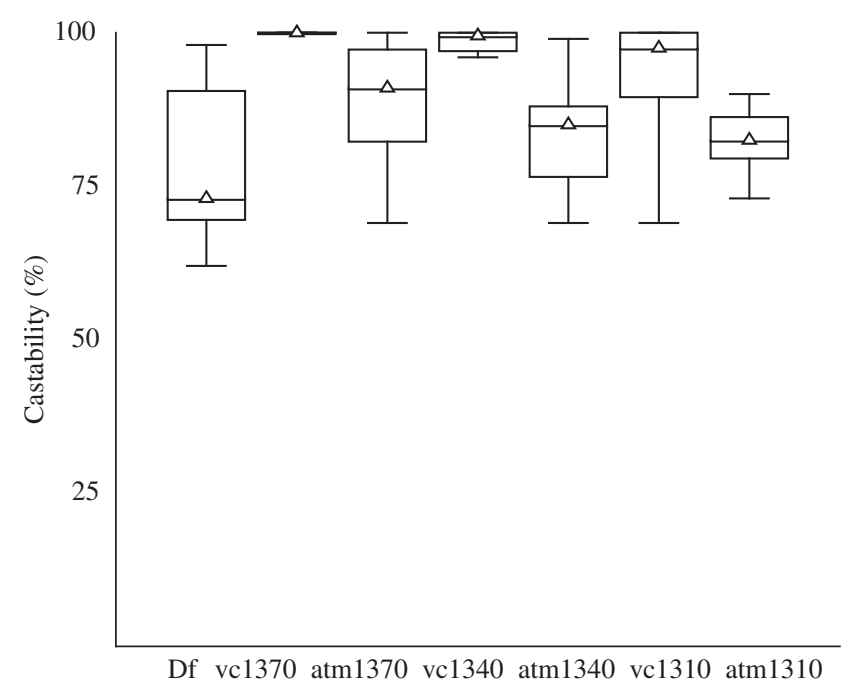

Figure 3. Box plot of castability values of VB2 alloy. 


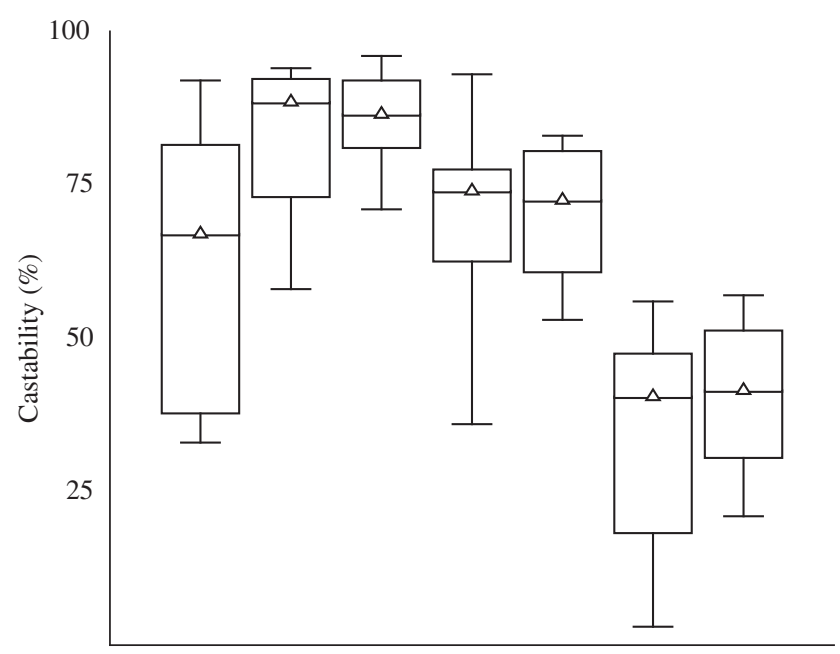

Df vc1460 atm1460 vc1430 atm1430 vc1400 atm1400

Figure 4. Box plot of castability values of W99 alloy.

Table 3. Mean + Standard deviation of alloys' castability for each cast condition, grouped by temperatures*.

\begin{tabular}{llr}
\hline Alloy & Cast condition & Castability \\
\hline VB & $1310^{\circ} \mathrm{C}$ & $97.9+7.37^{\mathrm{a}}$ \\
& Df & $96.2+3.08^{\mathrm{a}}$ \\
& $1340^{\circ} \mathrm{C}$ & $95.75+5.31^{\mathrm{a}}$ \\
& $1370^{\circ} \mathrm{C}$ & $94.9+7.37^{\mathrm{a}}$ \\
\hline VB2 & $1370^{\circ} \mathrm{C}$ & $94.4+8.76^{\mathrm{a}}$ \\
& $1340^{\circ} \mathrm{C}$ & $91.15+3.69^{\mathrm{a}}$ \\
& $1310^{\circ} \mathrm{C}$ & $87.9+9.38^{\mathrm{b}}$ \\
& $\mathrm{Df}$ & $77.8+12.65^{\mathrm{c}}$ \\
\hline W99 & $1460^{\circ} \mathrm{C}$ & $84.3+10.47^{\mathrm{a}}$ \\
& $1430^{\circ} \mathrm{C}$ & $70.3+13.01^{\mathrm{b}}$ \\
& $\mathrm{Df}$ & $62.5+22.80^{\mathrm{b}}$ \\
& $1400^{\circ} \mathrm{C}$ & $37.05+15.22^{\mathrm{c}}$ \\
\hline
\end{tabular}

*Groups with the same superscripted letter were not significantly different $(\mathrm{P}<0.05)$.

Table 4. Mean \pm Standard deviation of alloys' castability for each cast condition, grouped by casting atmosphere*.

\begin{tabular}{lcc}
\hline Alloy & Cast condition & Castability \\
\hline VB & vc & $99.3+1.62^{\mathrm{a}}$ \\
& Df & $96.2+3.08^{\mathrm{b}}$ \\
& atm & $93.06+6.3^{\mathrm{b}}$ \\
\hline VB2 & vc & $97.33+6.26^{\mathrm{a}}$ \\
& atm & $84.96+8.11^{\mathrm{b}}$ \\
& Df & $77.8+12.65^{\mathrm{b}}$ \\
\hline W99 & atm & $65.53+21.65^{\mathrm{a}}$ \\
& vc & $62.23+25.94^{\mathrm{a}}$ \\
& Df & $62.5+22.80^{\mathrm{a}}$ \\
\hline
\end{tabular}

*Groups with the same superscripted letter were not significantly different $(\mathrm{P}<0.05)$.

atmosphere and Df (Table 4). For VB2 the castability in Df $(77.8 \%)$ was significantly different in contrast to $1310^{\circ} \mathrm{C}(87.9 \% ; \mathrm{P}<0.05)$, $1340{ }^{\circ} \mathrm{C}(91.15 \% ; \mathrm{P}<0.01)$ and $1370{ }^{\circ} \mathrm{C}(94.4 \% ; \mathrm{P}<0.01)$. There was significant difference between $1370{ }^{\circ} \mathrm{C}$ and $1310^{\circ} \mathrm{C}(\mathrm{P}<0.05)$
Table 5. Mean \pm Standard Deviation of alloys' castability for each cast condition*.

\begin{tabular}{llc}
\hline Alloy & Cast condition & Castability \\
\hline VB & vc1310 & $100.0+0.0^{\mathrm{a}}$ \\
& vc1340 & $99.3+1.49^{\mathrm{a}}$ \\
& vc1370 & $98.6+2.27^{\mathrm{a}}$ \\
& Df & $96.2+3.08^{\mathrm{b}}$ \\
& atm1310 & $95.8+3.15^{\mathrm{b}}$ \\
& atm1340 & $92.2+5.41^{\mathrm{b}}$ \\
& atm1370 & $91.2+8.90^{\mathrm{b}}$ \\
\hline VB2 & vc1370 & $100.00+0.0^{\mathrm{a}}$ \\
& vc1340 & $98.7+1.56^{\mathrm{ab}}$ \\
& vc1310 & $93.3+9.78^{\mathrm{b}}$ \\
& atm1370 & $88.8+9.62^{\mathrm{b}}$ \\
& atm1340 & $83.6+8.31^{\mathrm{bc}}$ \\
& atm1310 & $82.5+5.03^{\mathrm{bc}}$ \\
& Df & $77.8+12.65^{\mathrm{c}}$ \\
\hline W99 & atm1460 & $85.8+7.99^{\mathrm{a}}$ \\
& vc1460 & $82.8+12.76^{\mathrm{a}}$ \\
& atm1430 & $70.6+10.40^{\mathrm{b}}$ \\
& vc1430 & $70.0+15.78^{\mathrm{b}}$ \\
Df & $62.5+22.80^{\mathrm{b}}$ \\
& atm1400 & $40.2+11.83^{\mathrm{c}}$ \\
& vc1400 & $33.9+18.09^{\mathrm{c}}$ \\
\hline
\end{tabular}

*Groups with the same superscripted letter were not significantly different $(\mathrm{P}<0.05)$.

(Table 3). The castability in Df was also considerably different from $\mathrm{vc}(97.33 \% ; \mathrm{P}<0.01)$ but not from atm $(87.9 \%)$. There was significant difference between vc and atm $(\mathrm{P}<0.01)$. For W99, while variation in the atmosphere did not relevantly affect castability, the mold filling at $1460{ }^{\circ} \mathrm{C}(84.3 \%), 1430{ }^{\circ} \mathrm{C}(70.3 \%)$ and $1400{ }^{\circ} \mathrm{C}(37.05 \%)$ was significantly different $(\mathrm{P}<0.01)$. The castability in Df $(62.5 \%)$ was considerably different between $1460{ }^{\circ} \mathrm{C}(\mathrm{P}<0.01)$ and $1400{ }^{\circ} \mathrm{C}$ $(\mathrm{P}<0.01)$. Comparison among interactions is summarized in Table 5 and shows that for all alloys it was possible to significantly increase the percentage of mold filling in comparison with the direct flame cast method. For VB and VB2 the mold filling was of $100 \%$ when the combinations of vc1310 and vc1370, respectively, were used. In the case of W99, the interaction atm 1460 resulted in the best castability value $(85.8 \%)$ for this alloy and was approximately $40 \%$ higher than under Df conditions.

\section{Discussion}

When metal frameworks for fixed or removable partial denture are refused at initial clinical trial, it is likely that defects occurred when copying of minimal details of the wax pattern was performed. At this time, frameworks are seldomly discarded for deficiency on other properties that are not on castability.

When dental alloys are cast by direct gas-oxygen flame, the visual control of this casting method is the only criterion with which to decide the precise moment to start centrifugation. Therefore, the procedure is vitally dependent on the technician's ability to find that critical moment. In such situations, the defect may represent to be more of a failure in the casting procedure than in the quality of the alloy. 
The present study evaluated the effect of casting temperature and controlled atmosphere, comparing it with direct gas-oxygen flame on the castability of three brands of base metal alloys. In order to choose the temperatures used for each alloy, the melting range given by the manufacturers and the appearance of the molten alloy inside the crucible before centrifugation were observed. The highest temperature, to which they could be submitted without any evidence of over-heating, was determined for each alloy. Thus, temperature was reduced by $30{ }^{\circ} \mathrm{C}$ and $60{ }^{\circ} \mathrm{C}$ based on the premise that some variations could occur during direct flame casting method and that these variations are dependent solely on the technician's experience. It is important to take into consideration that the highest temperature used was sometimes $100{ }^{\circ} \mathrm{C}$ or $150{ }^{\circ} \mathrm{C}$ higher than the temperature indicated by the manufacturer.

For all alloys, we were able to find more than one temperature/ atmosphere combination, which significantly improved castability under the conditions chosen in this study, compared with direct flame casting method.

It was clear that, with exception of W99, vacuum casting improved the castability of the alloys, where the range of adopted temperature was less important. The vacuum reduces back pressure, thereby facilitating mold filling, especially in the fine details ${ }^{11}$. For W99, the reduction in temperature resulted in a significantly decreased castability, regardless of the casting atmosphere, thereby demonstrating the great sensitivity of this alloy to temperature variations and the low influence of casting atmosphere. It is important to considerer that at temperatures over $1460{ }^{\circ} \mathrm{C}$, besides the risk of over heating, the percentage of mold filling did not improve.

For VB, unlike the other alloys, the castability was not affected by a temperature reduction. This was probably due to the presence of beryllium in its composition, which reduces the cast temperature and provides a wider range of cast temperature, thereby facilitating the casting process. This was evident based on the excellent castability values from direct flame cast method. Probably, if the temperature range were set at $1310{ }^{\circ} \mathrm{C}$ and under, the temperature effect would be evident.

For VB2 and W99, in which temperature reduction is a significant aspect, the result from direct flame cast method, compared with controlled cast conditions, suggests that the technician underwent greater difficulty in determining the ideal moment for centrifugation. Besides, the direct flame casting method can included gas and may damage the castability. While for VB2, and W99 the combinations of vc1370 and atm1460 increased the percentage of filling by more than $20 \%$ and $30 \%$, respectively, compared with direct flame casting method, for VB, the improvement in castability, although significant, was less relevant, from a practical perspective, because of the high percentage of filling with direct flame cast method.

The graphic analysis shows that some combinations, such as atmosphere/temperature: vc1340, vc1310 for VB and vc1370 for VB2 provided very low variability in the castability results.

The chosen method for determination of castability enables only a comparative study of different casting conditions or materials, but it does not determine the clinical success of any material or technique. Good clinical results have been obtained in fixed and removable prostheses with alloys that do not reproduce the mesh totally. Consequently, working in controlled casting conditions allows determining a protocol that guarantees the necessary fluidity for adequate clinical fit of the restoration, thus avoiding any possibility of over or under-heating.

It is important to consider that all direct flame casting methods were carried out by an experienced technician during the manipulation routine of the three alloys brands. Thus, the good castability values obtained by direct flame casting method were not surprising.
Even so, it was possible to increase the castability of all alloys by controlling casting conditions.

These results guide us to reflect on the technician's ability and the transference of this ability to another technician. Training the operator, which results in correct regularity of the flame and to adequately view and know the exact moment of the alloy melting for centrifugation release, is not something that is easily transferred to another operator.

In previous tests to determine the range of temperature for each alloy $\left(1310^{\circ} \mathrm{C}\right.$ to $1370{ }^{\circ} \mathrm{C}$, for VB and VB2; and $1400{ }^{\circ} \mathrm{C}$ to $1460{ }^{\circ} \mathrm{C}$ for W99), higher values than the ones used in this study produced well defined over-heating, which damaged the results as well as the appearance of the sample tests. Such over-heating was easily detected by visual observation, such as turbulence of the molten alloy inside the crucible. Nevertheless, lower values made the alloy not sufficiently molten to run and fulfill the mold, i.e., the alloy seemed to be too liquefied to inject by centrifugation, but was not observed by visual control, which made the castability values decrease. Thus, if over-heating of the alloys can be easily observed, under-melting it may not, and could endanger the results. This way, detecting the ideal moment to operate centrifugation, without an indicative of the casting temperature, is an operation which demands quite a bit of training. On the other hand, an established protocol developed in a laboratory for adjustment of a piece of equipment may be easily performed by any professional.

Within the limits of this study, it was concluded that for each material it is possible to define an optimal combination of casting temperature and atmosphere, and thereby take advantage of the maximum ability of the materials to reproduce fine details of the wax pattern, which is essential for successful metal casting restorations. The use of controlled casting conditions reduces operator error in direct flame casting methods. Further studies should investigate controlling other characteristics not considered in this study, such as mold temperature, centrifugation torque and different brands of investment.

\section{Acknowledgments}

The present study was partially funded by grant No. 96/11874-4 from the State of São Paulo Research Foundation (FAPESP), and grant number. 301080/91-7 (RN) from the National Council for Scientific and Technological Development (CNPq).

\section{References}

1. Peregrina A, Schorr BL, Eick JD, Robinson SJ, Feil PH. Measurement of oxide adherence to silver-free high-palladium alloys. International Journal of Prosthodontics. 1992; 5(2):173-178.

2. Bezzon OL. Allergic sensitivity to several base metals-A clinical report. Journal of Prosthetic Dentistry. 1993; 69(3):243-244.

3. Cohen SM, Kakar A, Vaidyanathan TK, Viswanadhan T. Castability optimization of palladium based alloys. Journal of Prosthetic Dentistry. 1996; 76(2):125-131.

4. Luk HW, Darvell BW. Casting system effectiveness-measurement and theory. Dental Materials. 1992; 8(2):89-99.

5. Cohen SM, Vaidyanathan TK, Tanabe N. Digital imaging techniques for dental alloy castability quantification. Journal of Oral Rehabilitation. 1992; 19(3):297-308.

6. Bezzon OL, Ribeiro RF, Rollo JMDA, Crosara S. Castability and resistance of ceramometal bonding in $\mathrm{Ni}-\mathrm{Cr}$ and $\mathrm{Ni}-\mathrm{Cr}-\mathrm{Be}$ alloys. Journal of Prosthetic Dentistry. 2001; 85(3):299-304.

7. Bezzon OL, de Mattos MGC, Ribeiro RF, Rollo JMDA. Effect of beryllium on the castability and resistance of ceramometal bonds in nickel-chromium alloys. Journal of Prosthetic Dentistry. 1998; 80(5):570574. 
8. O'Connor RP, Mackert Jr JR, Myers ML, Parry EE. Castability, opaque masking, and porcelain bonding of 17 porcelain-fused-to-metal alloys. Journal of Prosthetic Dentistry. 1996; 75(4):367-374.

9. Johnson A, Winstanley RB. The evaluation of factors affecting the castability of metal ceramic alloy-investment combinations. International Journal of Prosthodontics. 1996; 9(1):74-78.

10. Chern Lin JH, Chen YF, Ju CP. Effect of nickel addition on microstructure and properties of Ti-Co-Ni alloys. Biomaterials. 1995; 16(18):14011407.
11. Hero H, Waarli M. Effect of vaccum and supertemperature on mold filling during casting. Scandinavian Journal of Dental Research. 1991; 99(1):55-59.

12. Hirano S, Tesk JA, Hinman RW, Argentar H, Gregory TM. Casting of dental alloys: mold and alloy temperature. Dental Materials. 1987; 3(6):307-314.

13. Hinman RW, Tesk JA, Whitlock RP, Parry EE, Durkowski JS. A technique for characterizing casting behavior of dental alloys. Journal of Dental Research. 1985; 64(2):134-138. 